\title{
Review Article \\ Strategies for Lipid Production Improvement in Microalgae as a Biodiesel Feedstock
}

\author{
L. D. Zhu, ${ }^{1,2}$ Z. H. Li, ${ }^{2}$ and E. Hiltunen ${ }^{1}$ \\ ${ }^{1}$ Faculty of Technology, University of Vaasa and Vaasa Energy Institute, P.O. Box 700, 65101 Vaasa, Finland \\ ${ }^{2}$ Hubei Collaborative Innovation Center for Green Transformation of Bio-Resources and Faculty of Resources \\ and Environmental Science, Hubei University, Wuhan 430062, China
}

Correspondence should be addressed to L. D. Zhu; zliand@uva.fi

Received 26 May 2016; Revised 20 July 2016; Accepted 25 July 2016

Academic Editor: Ramkrishna Sen

Copyright (C) 2016 L. D. Zhu et al. This is an open access article distributed under the Creative Commons Attribution License, which permits unrestricted use, distribution, and reproduction in any medium, provided the original work is properly cited.

In response to the energy crisis, global warming, and climate changes, microalgae have received a great deal of attention as a biofuel feedstock. Due to a high lipid content in microalgal cells, microalgae present as a promising alternative source for the production of biodiesel. Environmental and culturing condition variations can alter lipid production as well as chemical compositions of microalgae. Therefore, application of the strategies to activate lipid accumulation opens the door for lipid overproduction in microalgae. Until now, many original studies regarding the approaches for enhanced microalgal lipid production have been reported in an effort to push forward the production of microalgal biodiesel. However, the current literature demonstrates fragmented information available regarding the strategies for lipid production improvement. From the systematic point of view, the review highlights the main approaches for microalgal lipid accumulation induction to expedite the application of microalgal biodiesel as an alternative to fossil diesel for sustainable environment. Of the several strategies discussed, the one that is most commonly applied is the design of nutrient (e.g., nitrogen, phosphorus, and sulfur) starvation or limitation. Other viable approaches such as light intensity, temperature, carbon dioxide, salinity stress, and metal influence can also achieve enhanced microalgal lipid production.

\section{Introduction}

Energy crisis, global warming, and climate changes have led to an ever-increasing concern on the sustainability issues of fossil fuels utilization as energy supply. Biofuels as types of renewable, alternative energy are recognized with the highest potential to satisfy the global energy demand. The biofuel feedstock mainly consists of the following sources: straw, wood materials, wood wastes, energy plants, sugarcane, manure, and many other agricultural coproducts or byproducts [1]. It is believed that biofuel production has several advantages such as reduction of country's reliance on crude oil imports, job creation, and farmers' income increase [24]. On the basis of feedstock differences, biofuels can be divided into three categories: the first generation, the second generation, and the third generation. First generation biofuels use edible feedstock such as soya beans, wheat, corn, rapeseed, oil crops, maize, sugarcane, and sugar beet, while second generation biofuels are derived from wastes and dedicated lignocellulosic feedstock such as switchgrass and jatropha [5]. One of the major disadvantages of both first and second generation biofuels is that the cultivation of these food or nonfood crops as biofuel feedstock might compete for limited arable farmland, which should be utilized to cultivate crops as food feedstock. Thus, biofuels are not considered renewable and sustainable if they are derived from food or nonfood crops [6]. Biofuel production from food crops grown in farmland will affect food security and prices, while the cultivation of nonfood energy crops will result in competition with food crops for farmland.

In response to the challenges outlined above, microalgae have received a global attention as a promising biofuel feedstock. Compared to first and second generation biofuel feedstock, microalgae as third generation biofuel feedstock have some distinguishable features, such as high photosynthetic efficiency, rapid growth, high lipid content, high $\mathrm{CO}_{2}$ mitigation efficiency, noncompetition with food crops for farmland, and less water demand than land crops [5, 7-9]. 
As photosynthetic organisms, microalgae are able to capture solar energy and use water and atmospheric $\mathrm{CO}_{2}$ to accumulate biomass in forms of organic ingredients such as lipids [10]. During the photosynthesis, neutral lipids are accumulated as triacylglycerols (TAGs) in microalgal cells [11]. Through transesterification, TAGs can be further transferred into various types of fatty acid methyl esters, the efficient compositions of biodiesel.

To generate large amount of microalgal biomass and meet the energy consumption demand, mass scale microalgal cultivation for biodiesel production is a plausible solution in the future [12]. Meanwhile, the improvement of lipid content in microalgal cells also presents a direction towards the sustainable development of microalgal biodiesel. Thus, it is extremely important to apply feasible strategies to induce microalgal lipid accumulation. The production and accumulation of microalgal lipids are found to be an indispensable buffer against the culturing conditions. Stored lipids not only ensure the survival of microalgal cells but also serve as a source of energy for cell multiplication such as nuclear division and DNA replication [11].

Objective and Structure of This Study. Plenty of original research articles that exactly investigate certain strategies for enhanced microalgal lipid production have been published. These strategies play crucial roles in triggering microalgal lipid accumulation. However, the current literature has not systematized all of the most promising strategies, and there is only fragmented information available. In other words, as yet, no comprehensive review has been published on those strategies for enhanced microalgal lipid production. Therefore, this review aims to bridge the gap and its objective is to systematically concentrate on the main lipid induction strategies that can evidently promote microalgal lipid production. The contribution of this review paper lies in the foundation for stakeholders, authorities, and practitioners to better understand microalgal lipid induction strategies and their significances in practice. In the coming parts, the authors first illustrate the metabolic pathways of lipid accumulation (Section 2), followed by the comprehensive discussion of approaches for lipid production improvement (Section 3). Finally, a summary of this article is concluded (Section 4).

\section{Metabolic Pathways of Lipid Accumulation}

The research on lipid-rich microalgal cultivation for biodiesel production has received an increased interest. Lipids and polyglucans are the energy and carbon reserves in microalgal cells, but polyglucans represent less concentrated stores of metabolic energy than lipids [11]. Both lipids and polyglucans not only ensure the survival of microalgal cells such as in night periods as well as in periods with variable light intensities but also supply energy for biological processes associated with the multiplication of microalgal cells, such as the replication of DNA, division of nuclear, cytokinesis, and formation and liberation of daughter cells. According to Berg et al. [13], the complete oxidation of fatty acids can generate energy at $9 \mathrm{kcal} \mathrm{g}^{-1}\left(38 \mathrm{~kJ} \mathrm{~g}^{-1}\right)$, compared to around $4 \mathrm{kcal} \mathrm{g}^{-1}$
(17 $\mathrm{kJ} \mathrm{g}^{-1}$ ) for carbohydrates. Lipids include two types: neutral lipids that serve as the energy reserves and polar lipids that are constituents of organelles and membranes. Microalgal cells accumulate and store neutral lipids in the form of triacylglycerols (TAGs).

Microalgal cell cycle contains several consecutive procedures, including cell growth, DNA replication, nuclear division, and cellular division. Metabolism of both starch and lipid begins with an identical initial pool of molecules containing three carbons such as glyceraldehyde 3-phosphate (GAP) and 3-phosphoglycerate (3PG) [14]. Figure 1 illustrates metabolic pathways that influence the accumulation of lipids by common C3 precursors. As for autotrophic microalgae, light capture for photosynthesis is crucial for microalgal growth to accumulate energy reserves such as lipids. As a result, DNA replication and nuclear and cellular division in cell cycle can be completed through the utilization of the reserves to meet requirements of carbon and energy [15].

The formation of both TAG and starch competes for carbon via common $\mathrm{C} 3$ precursors, resulting in carbon partitioning. However, the mechanism behind carbon partitioning together with the switch from starch towards the production of TAG has not been completely understood in the literature. When the route towards starch formation is inhibited, the pathway towards the formation of TAG molecules is improved [16]. Li et al. [17] suggested that the starch content of starchless mutants of microalgae $C$. reinhardtii was limited or even completely absent, leading to an increased TAG content in contrast to the wild type. Despite the increase in TAG content, Li et al. [18] found that growth of starchless microalgae $C$. reinhardtii was markedly inhibited by the inserted mutation, giving rise to the decrease of TAG productivity.

\section{Approaches to Lipid Production Improvement}

The composition and quantity of lipids are species-dependent and can be affected by external cultivation conditions, such as light intensity, temperature, carbon dioxide, nutrient starvation, salinity stress, and metal stress. The overproduction or overaccumulation of lipid reserves presents an indispensable buffer against changeable external cultivation conditions.

3.1. Light Intensity. Microalgal growth needs the input of light during the photosynthesis. As one of the key factors, light affects the performances of microalgal growth and the compositions [5]. Adequate light intensity favors the overproduction of microalgal lipids [19]. This might be because sufficient light intensity is beneficial to the storage of excess photoassimilates, which are further converted into chemical energy [20]. Microalga Nannochloropsis sp. experienced the accumulation of the highest amount of lipids ( $47 \%$ of DW) under the conditions with the highest light intensity (700 $\mu$ mol photons s $\mathrm{m}^{-1} \mathrm{~m}^{-2}$ ) [21]. Takeshita et al. [22] found that C. sorokiniana, C. viscosa, C. emersonii, C. vulgaris, P. beijerinckii, and P. kessleri CCALA255, NIES-2152, and NIES2159 were able to increase the productivity of lipids under high light intensity of $600 \mu \mathrm{mol}$ photons $\mathrm{m}^{-2} \mathrm{~s}^{-1}$. It has been 


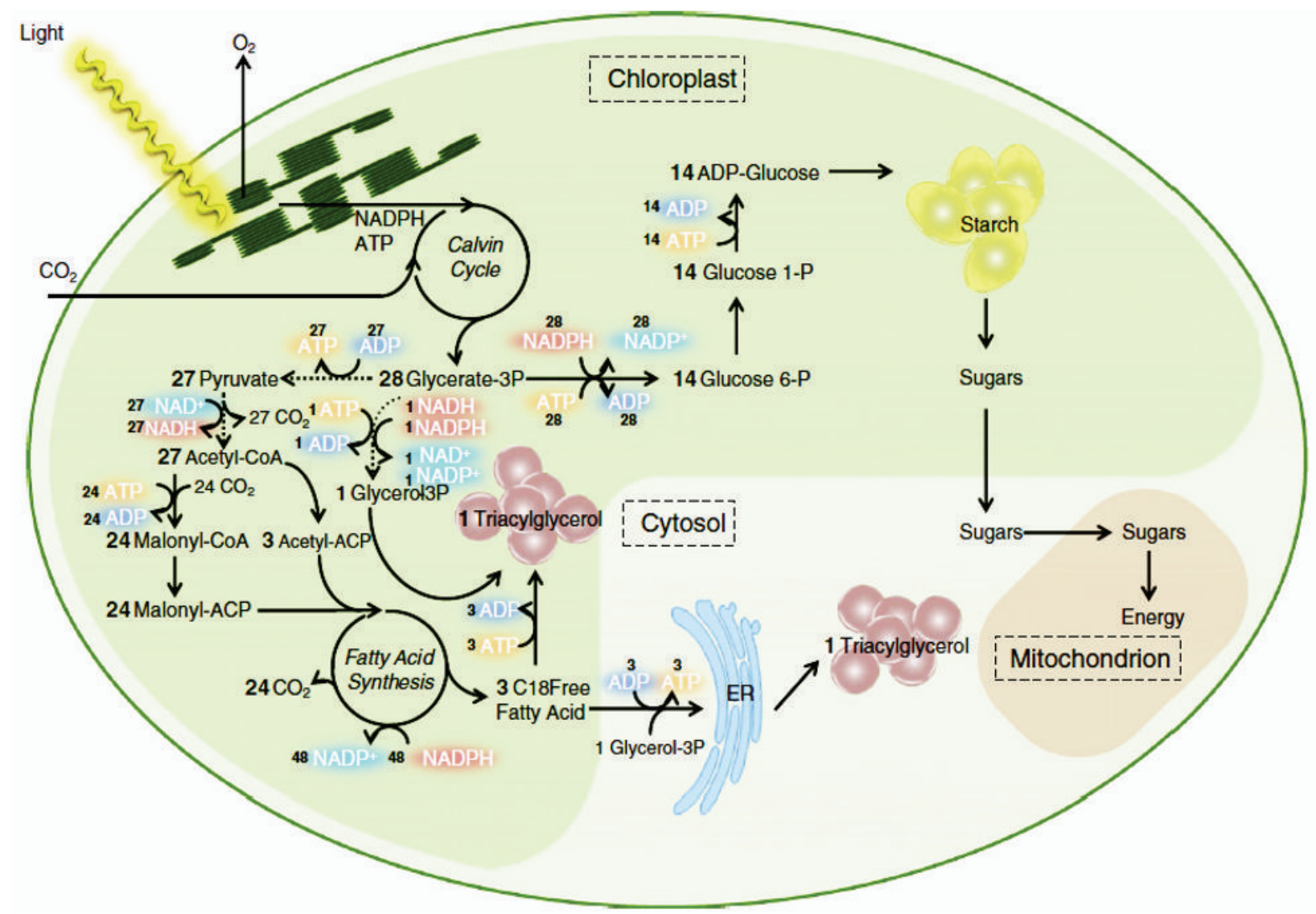

Figure 1: Simplified triacylglycerol (TAG) metabolism in green microalgae [14]. The dashed lines refer to the reactions that occur in the cytosol. The figure illustrates two possible pathways for TAG formation following the assumed route in the chloroplasts or over the endoplasmic reticulum (ER) membranes in the cytosol.

seen that the lipid content of the microalgae Scenedesmus abundans kept on rising as the light intensity increased from 3000 to 6000 lux [23]. The highest lipid content of $32.77 \%$ was achieved, when the culture was under the light intensity of $6000 \mathrm{lux}$, followed by 27.10 and $21.20 \%$ in the culture with 5000 and 3000 lux intensity, respectively. Another study indicated that Botryococcus sp. had shown the highest lipid percentage (35.9\%) at 6000 lux [24]. However, Sun et al. [25] suggested that highest lipid percentage (33.0\%) of microalgae $N$. oleoabundans HK-129 was achieved at 14,800 lux intensity. Thus, different microalgal species have the highest lipid content at variable light intensities, since they indicate different efficiencies in light utilization. From this point of view, the ability to use light is microalgae-specific.

Either limited or saturated light intensity cannot favor the growth of microalgae. When light intensity is fairly low, for example, below the compensation point, microalgal biomass concentration compromises, leading to poor growth and thus negatively impacting lipid accumulation [5]. After the compensation point, microalgae experience the increased growth as the light intensity increases, and the maximum photosynthetic efficiency occurs when it arrives at the light saturation point. Therefore, the positive effect of light intensity increases on lipid accumulation functions only up to a point [11]. Extremely high light intensity will cause photoinhibition, damage microalgal photosystems, and thus reduce lipid accumulation.

3.2. Temperature. The effect of temperature on microalgal growth and lipid production is similar to that of light intensity. Microalgal growth as well as lipid production exponentially increases to a certain extent as the temperature increases and reaches an optimal level [26]. The optimal value of temperature where the highest biomass production is achieved varies from species to species [27]. Microalgae C. vulgaris accumulated maximum lipids at $25^{\circ} \mathrm{C}$, while the decrease of temperature resulted in an obvious decrease in the lipid content [28]. The temperature of $20^{\circ} \mathrm{C}$ was found to be the optimal temperature for microalgae Scenedesmus sp. to produce lipids [29]. The lipid concentration of microalgae $S$. obliquus ranged from 18 to $40 \%$ of DW, when the temperature ranged from 20 to $27.5^{\circ} \mathrm{C}$ [11]. Converti et al. [28] suggested that as the temperature increased from 20 to $25^{\circ} \mathrm{C}$, the lipid content of $N$. oculata simultaneously increased from 7.9 to $14.9 \%$. In another study, the optimum temperature of $C$. minutissima was found to be $20^{\circ} \mathrm{C}$, where lipid productivity was the highest [30]. 
Increase of temperature to an optimal level causes the increase of total lipid content. However, it does not mean that all types of lipids experience the increase. Wei et al. [31] studied temperature effects on lipid properties of microalgae Tetraselmis subcordiformis and Nannochloropsis oculata and found that increased temperature led to a decrease in neutral lipids and polyunsaturated fatty acids but an increase in saturated and monounsaturated fatty acids. Likewise, James et al. [32] investigated temperature modulation of fatty acid profiles for microalgae Chlamydomonas reinhardtii and suggested that a switch to temperatures lower than $25^{\circ} \mathrm{C}$ could decrease the total amount of stored fatty acids but increase the content of unsaturated fatty acids.

3.3. Carbon Dioxide. As for phototrophic microalgae, $\mathrm{CO}_{2}$ ensures carbon supply for photosynthesis. Optimal growth of microalgae needs adequate amount of dissolved $\mathrm{CO}_{2}$. In general, as the quantity of $\mathrm{CO}_{2}$ increases to an optimal level, the growth of microalgae and production of lipids increase. Aeration of gas mixture with a high concentration of $\mathrm{CO}_{2}$ can meet the requirement for $\mathrm{CO}_{2}$. The amount of $\mathrm{CO}_{2}$ in atmospheric air is not sufficient. Li et al. [33] suggested that aeration with pure air resulted in a decrease in growth and lipid production of microalgae Parachlorella kessleri. Limited amount of $\mathrm{CO}_{2}$ available in cultures slows down the metabolism of microalgae, causing reduced lipids [34]. To reduce costs, flue gas (rich in $\mathrm{CO}_{2}$ ) can be introduced into microalgal culturing systems as a carbon source. However, high content of $\mathrm{CO}_{2}$ will also affect the growth of microalgae. This is because unutilized $\mathrm{CO}_{2}$ in culture will be converted to carbonic acid $\left(\mathrm{H}_{2} \mathrm{CO}_{3}\right)$, reducing the $\mathrm{pH}$ value of the culture [27]. Therefore, to obtain enhanced biomass and lipid production requires optimal $\mathrm{CO}_{2}$ levels.

The optimal amount of $\mathrm{CO}_{2}$ varies among microalgal species. Cultivating microalgae Chlorella vulgaris under $8 \%$ (v/v) $\mathrm{CO}_{2}$, Montoya et al. [35] achieved the maximum amount of saturated fatty acids and lipid productivity of $29.5 \mathrm{mg} \mathrm{L}^{-1}$ day $^{-1}$. Similarly, Widjaja et al. [36] reported that the growth and lipid production of $C$. vulgaris were enhanced with increased $\mathrm{CO}_{2}$ concentration. The microalgae Chlamydomonas sp. JSC4 strain produced maximum lipid content $(65.3 \%)$ and productivity $\left(169.1 \mathrm{mg} \mathrm{L}^{-1} \mathrm{day}^{-1}\right)$ at $4 \%(\mathrm{v} / \mathrm{v})$ $\mathrm{CO}_{2}$ [37]. Maximum lipid content (34\% wt) was achieved, when microalgae Chlorococcum littorale were cultivated with $5 \% \mathrm{CO}_{2}$ concentration [38]. In another study, Ho et al. [39] grew green microalgae $S$. armatus at $\mathrm{CO}_{2}$ concentration of $2 \%$ and obtained the highest lipid content of $22.4 \%$.

3.4. Nutrient Starvation. Nutrient starvation or limitation is thought to be a feasible and environmentally friendly approach for the control of the cell cycle to enhance lipid productivity [40]. So far, nutrient starvation is recognized as the most successful strategy and most widely used. In an attempt to improve lipid productivity, it is important to obtain both substantial biomass yield and high lipid content of microalgal cells. In practice, algae are grown in media with sufficient nutrients in early stages to obtain higher biomass concentration as quickly as possible, while nutrient starvation is introduced in later stages for the overproduction of lipids.

Variation in macronutrients such as nitrogen, phosphorus, and sulfur in culturing media will lead to the alteration of macromolecular composition in microalgal cells. Under nutrient stress, lipid accumulation is favored, and TAG is formed as the dominant ingredient [27]. Plenty of studies have reported that most microalgal species can improve lipid accumulation and undergo transformation under nutrient stress [41-43]. Nevertheless, as for some species nutrient deficiency will not favor the accumulation of lipids. For instance, under nutrient deficiency the microalgae Dunaliella salina experienced lipid content decrease from 25 to $9 \%$ but carbohydrate increase from 16 to $56 \%$ [44].

Nitrogen, phosphorus, and/or sulfur starvation is widely recognized as a main lipid inducer for green microalgae species (Table 1). Ito et al. [45] reported that under nitrogen stress conditions the quantities of neutral lipids in microalgal cells were greatly increased, while amino acids were significantly reduced to $1 / 20$ of the amount or even less. Mandal and Mallick [46] cultivated the microalgae Scenedesmus obliquus under phosphorus starvation and witnessed a lipid content increase from 10.0 to $29.5 \%$. Sato et al. [47] suggested that sulfur starvation could trigger the microalgae Chlamydomonas reinhardtii to accumulate TAG in microalgal cells through the diversion of metabolic carbon-flow from protein to TAG synthesis. Apart from nitrogen, phosphorus, and sulfur starvation, depletion of nutrient medium during the growth of microalgal culture has also been found as another efficient starvation treatment for the production of lipids, since the starvation of all elements in nutrient media can be attained concurrently [11, 48]. For example, Pribyl et al. [49] found that the total extractable lipid content could reach up to $57.25 \%$, when $C$. vulgaris was cultivated under nutrient depletion conditions for 7 days.

3.5. Salinity Stress. To resist osmotic pressure due to salinity stress, some metabolites in microalgal cells can be produced [50]. Surrounding salinity can affect the physiological and biochemical properties of microalgae. When microalgal cells are exposed to saline environment, recovery of turgor pressure, adjustment of the absorption and release of ions via cell membranes, and accumulation of osmosis-resisting matters are triggered $[51,52]$. The salinity stress created inside the cells results in increment in the lipid content. Many microalgal species have been found to be subjected to the salinity stress. Yang et al. [53] applied $\mathrm{NaCl}$ induction with the optimal salt concentration at the late-exponential growth phase and found that the algae Monoraphidium dybowskii could increase total lipid content to $41.7 \%$ in a day. Pal et al. [21] investigated the effect of $\mathrm{NaCl}$ on the growth of $\mathrm{Nan}$ nochloropsis sp. and reported that the highest total fatty acid (TFA) content of $47.0 \%$ DW and average lipid productivity of $360 \mathrm{mg} \mathrm{TFA} \mathrm{L}^{-1}$ day $^{-1}$ were achieved at $13 \mathrm{~g} \mathrm{~L}^{-1} \mathrm{NaCl}$. When exposed to salt pressure, Scenedesmus species experienced an obvious increase in lipid content [54]. Takagi et al. [55] studied the effect of salt concentration on intracellular accumulation of lipids and triacylglycerol in marine microalgae Dunaliella cells and found that as salt concentrations 
TABLE 1: Lipid content of microalgae under the cultivation with nutrient stress factor.

\begin{tabular}{|c|c|c|c|c|c|c|}
\hline Microalgae & Stress factor & $\begin{array}{c}\text { Temperature } \\
\left({ }^{\circ} \mathrm{C}\right) \\
\end{array}$ & $\begin{array}{c}\text { Culture time } \\
\text { (d) }\end{array}$ & $\begin{array}{c}\text { Metabolic } \\
\text { type }\end{array}$ & $\begin{array}{c}\text { Lipid content } \\
(\%)\end{array}$ & Reference \\
\hline Chlorella vulgaris & Nitrogen starvation & 25 & 10 & Autotrophic & 53 & {$[61]$} \\
\hline $\begin{array}{l}\text { Chlorella vulgaris and } \\
\text { Chlorococcum oleofaciens }\end{array}$ & Nitrogen starvation & 25 & 12 & Autotrophic & 35 and 40 & {$[62]$} \\
\hline Monoraphidium sp. & Nitrogen starvation & 25 & 5 & Autotrophic & 44.4 & {$[63]$} \\
\hline Chlorella zofingiensis & $\begin{array}{l}\text { Nitrogen starvation; } \\
\text { phosphorus starvation }\end{array}$ & 25 & 28 & Autotrophic & $65.1 ; 44.7$ & {$[64]$} \\
\hline Scenedesmus sp. & Nitrogen starvation & 25 & 10 & Mixotrophic & 31 & {$[65]$} \\
\hline Chlorella zofingiensis & $\begin{array}{l}\text { Nitrogen starvation; } \\
\text { phosphorus starvation }\end{array}$ & 25 & 8 & Mixotrophic & $41.2 ; 42.7$ & {$[41]$} \\
\hline Chlorella zofingiensis & $\begin{array}{l}\text { Nitrogen and } \\
\text { phosphorus starvation }\end{array}$ & 25 & 8 & Mixotrophic & 46.2 & {$[41]$} \\
\hline Ankistrodesmus falcatus & $\begin{array}{l}\text { Nitrogen starvation; } \\
\text { phosphorus starvation }\end{array}$ & 20 & 16 & Autotrophic & $34.4 ; 45.9$ & {$[66]$} \\
\hline Chlorella protothecoides & Phosphorus starvation & 28 & 7 & Mixotrophic & 32.8 & {$[42]$} \\
\hline Parachlorella kessleri & Sulfur deprivation & 20 & 14 & Autotrophic & 50.7 & {$[67]$} \\
\hline Chlorella lobophora & Sulfur deprivation & 20 & 21 & Autotrophic & 50.0 & {$[68]$} \\
\hline Parachlorella kessleri & $\begin{array}{l}\text { Depletion of diluted } \\
\text { nutrient media }\end{array}$ & 30 & 4 & Autotrophic & 60.0 & {$[33]$} \\
\hline
\end{tabular}

increased intracellular lipid content increased and the final lipid content could reach up to $70 \%$. Under salinity stress, $C$. vulgaris experienced a $21.1 \%$ increase of lipid yields [56].

Cultivation of microalgae under salt stress can also limit contaminants, invasive organisms, and competing microorganisms in microalgal systems, which presents another advantage. However, too high salinity introduced can inhibit the cell growth and change the shape and structure of microalgal cells, due to the water pressure between media and cells. Thus, an optimal range for salinity level is supposed to be determined.

3.6. Metal Stress. Metal ions can also affect the growth of microalgae and lipid production. Ren et al. [57] studied the effects of iron, magnesium, and calcium on biomass and lipid production of heterotrophic microalgae Scenedesmus sp. R-16 in a dark environment and found that the total lipid content increased to $43.2,35.0$, and $47.4 \%$, respectively. Another study showed that Chlorella minutissima UTEX 2341 indicated strong resistance to copper and cadmium ions under heterotrophic culture conditions, and the lipid content was significantly increased by 93.9 and $21.1 \%$, respectively [58]. Liu et al. [59] found that the total lipid content in cultures added with $1.2 \times 10^{-5} \mathrm{~mol} \mathrm{~L}^{-1} \mathrm{FeCl}_{3}$ reached up to $56.6 \%$ of dry weight and was 3-7-fold higher than other media added with lower iron concentrations. Yeesang and Cheirsilp [24] cultivated microalgae Botryococcus spp. in cultures added with a high iron concentration $(0.74 \mathrm{mM})$ and reported that the total lipid content was increased 1.42.5-fold. A study was carried out using Chlorella species under copper exposure to evaluate the metal stress on lipid contents, and it is found that higher lipid concentrations were observed in C. protothecoides, C. vulgaris, and C. pyrenoidosa in the presence of copper at $4.0 \mathrm{mg} \mathrm{L}^{-1}$ concentration. In addition, Li et al. [60] investigated the production of biomass and lipids by the microalgae Chlorella protothecoides under copper stress conditions and achieved the optimized biomass and lipid yield of 6.47 and $5.78 \mathrm{~g} \mathrm{~L}^{-1}$, respectively.

\section{Conclusions}

Microalgae have been praised as a promising feedstock for the production of biodiesel. Lipids, which are energy reserves in microalgal cells, are the raw materials for biodiesel conversion. To promote microalgal biodiesel production during the scale-up process, the achievement of lipid overproduction is essential, and certain appropriate strategies can help realize the goal. Among all strategies, the most efficient and widely used one is to apply nutrient starvation. Other approaches for the induction of lipid overaccumulation include light intensity, temperature, carbon dioxide, salinity stress, and metal stress. In practice, the lipid-inducing strategies can also be combined in an effort to achieve lipid production optimization. This review paper provides stakeholders, authorities, and practitioners with the foundation for better understanding microalgal lipid induction strategies and their significances in practice. There is hope that microalgae-based lipid production can be promoted through the application of various strategies.

\section{Competing Interests}

The authors declare no competing interests regarding the publication of this paper. 


\section{Acknowledgments}

This work was supported by the Kone Foundation in Finland. This work was also partially supported by the TransAlgae project funded by the Botnia-Atlantica programme and European Regional Development Fund.

\section{References}

[1] M. H. Langholtz, A. M. Coleman, L. M. Eaton, M. S. Wigmosta, C. M. Hellwinckel, and C. C. Brandt, "Potential land competition between open-pond microalgae production and terrestrial dedicated feedstock supply systems in the U.S.", Renewable Energy, vol. 93, pp. 201-214, 2016.

[2] H. Gunatilake, D. Roland-Holst, and G. Sugiyarto, "Energy security for India: biofuels, energy efficiency and food productivity," Energy Policy, vol. 65, pp. 761-767, 2014.

[3] L. Zhu, S. Huo, and L. Qin, "A microalgae-based biodiesel refinery: sustainability concerns and challenges," International Journal of Green Energy, vol. 12, no. 6, pp. 595-602, 2015.

[4] A. Chanthawong and S. Dhakal, "Stakeholders' perceptions on challenges and opportunities for biodiesel and bioethanol policy development in Thailand," Energy Policy, vol. 91, pp. 189206, 2016.

[5] L. Zhu, "Microalgal culture strategies for biofuel production: a review," Biofuels, Bioproducts and Biorefining, vol. 9, no. 6, pp. 801-814, 2015.

[6] L. Zhu, H. Shuhao, S. Shakeel, and Z. Li, "Algal biorefinery for sustainable development and the challenges," Proceedings of the Institution of Civil Engineers-Energy, 2016.

[7] F. Han, H. Pei, W. Hu, L. Jiang, J. Cheng, and L. Zhang, "Beneficial changes in biomass and lipid of microalgae Anabaena variabilis facing the ultrasonic stress environment," Bioresource Technology, vol. 209, pp. 16-22, 2016.

[8] L. Zhu, "The combined production of ethanol and biogas from microalgal residuals to sustain microalgal biodiesel: a theoretical evaluation," Biofuels, Bioproducts and Biorefining, vol. 8, no. 1, pp. 7-15, 2014.

[9] S. R. Medipally, F. M. Yusoff, S. Banerjee, and M. Shariff, "Microalgae as sustainable renewable energy feedstock for biofuel production," BioMed Research International, vol. 2015, Article ID 519513, 13 pages, 2015.

[10] L. Zhu, "Biorefinery as a promising approach to promote microalgae industry: an innovative framework," Renewable and Sustainable Energy Reviews, vol. 41, pp. 1376-1384, 2015.

[11] M. Vitova, K. Bisova, S. Kawano, and V. Zachleder, "Accumulation of energy reserves in algae: from cell cycles to biotechnological applications," Biotechnology Advances, vol. 33, no. 6, pp. 1204-1218, 2015.

[12] L. D. Zhu, Z. B. Xu, L. Qin, Z. M. Wang, E. Hiltunen, and Z. H. Li, "Oil production from pilot-scale microalgae cultivation: an economics evaluation," Energy Sources, Part B: Economics, Planning, and Policy, vol. 11, no. 1, pp. 11-17, 2016.

[13] A. H. Berg, T. P. Combs, and P. E. Scherer, "ACRP30/adiponectin: an adipokine regulating glucose and lipid metabolism," Trends in Endocrinology \& Metabolism, vol. 13, no. 2, pp. 84-89, 2002.

[14] L. de Jaeger, R. E. M. Verbeek, R. B. Draaisma et al., "Superior triacylglycerol (TAG) accumulation in starchless mutants of Scenedesmus obliquus: (I) mutant generation and characterization," Biotechnology for Biofuels, vol. 7, no. 1, article 69, 2014.
[15] K. Bišová and V. Zachleder, "Cell-cycle regulation in green algae dividing by multiple fission," Journal of Experimental Botany, vol. 65, no. 10, pp. 2585-2602, 2014.

[16] Z. T. Wang, N. Ullrich, S. Joo, S. Waffenschmidt, and U. Goodenough, "Algal lipid bodies: stress induction, purification, and biochemical characterization in wild-type and starchless Chlamydomonas reinhardtii," Eukaryotic Cell, vol. 8, no. 12, pp. 1856-1868, 2009.

[17] Y. T. Li, D. X. Han, G. R. Hu, M. Sommerfeld, and Q. A. $\mathrm{Hu}$, "Inhibition of starch synthesis results in overproduction of lipids in Chlamydomonas reinhardtii," Biotechnology and Bioengineering, vol. 107, no. 2, pp. 258-268, 2010.

[18] Y. Li, D. Han, G. Hu et al., "Chlamydomonas starchless mutant defective in ADP-glucose pyrophosphorylase hyper-accumulates triacylglycerol," Metabolic Engineering, vol. 12, no. 4, pp. 387-391, 2010.

[19] P. C. Hallenbeck, M. Grogger, M. Mraz, and D. Veverka, “The use of Design of Experiments and Response Surface Methodology to optimize biomass and lipid production by the oleaginous marine green alga, Nannochloropsis gaditana in response to light intensity, inoculum size and $\mathrm{CO}_{2}$," Bioresource Technology, vol. 184, pp. 161-168, 2015.

[20] A. E. Solovchenko, I. Khozin-Goldberg, S. Didi-Cohen, Z. Cohen, and M. N. Merzlyak, "Effects of light intensity and nitrogen starvation on growth, total fatty acids and arachidonic acid in the green microalga Parietochloris incisa," Journal of Applied Phycology, vol. 20, no. 3, pp. 245-251, 2008.

[21] D. Pal, I. Khozin-Goldberg, Z. Cohen, and S. Boussiba, "The effect of light, salinity, and nitrogen availability on lipid production by Nannochloropsis sp." Applied Microbiology and Biotechnology, vol. 90, no. 4, pp. 1429-1441, 2011.

[22] T. Takeshita, S. Ota, T. Yamazaki, A. Hirata, V. Zachleder, and S. Kawano, "Starch and lipid accumulation in eight strains of six Chlorella species under comparatively high light intensity and aeration culture conditions," Bioresource Technology, vol. 158, pp. 127-134, 2014.

[23] S. K. Mandotra, P. Kumar, M. R. Suseela, S. Nayaka, and P. W. Ramteke, "Evaluation of fatty acid profile and biodiesel properties of microalga Scenedesmus abundans under the influence of phosphorus, $\mathrm{pH}$ and light intensities," Bioresource Technology, vol. 201, pp. 222-229, 2016.

[24] C. Yeesang and B. Cheirsilp, "Effect of nitrogen, salt, and iron content in the growth medium and light intensity on lipid production by microalgae isolated from freshwater sources in Thailand," Bioresource Technology, vol. 102, no. 3, pp. 30343040, 2011.

[25] X. Sun, Y. Cao, H. Xu et al., "Effect of nitrogen-starvation, light intensity and iron on triacylglyceride/carbohydrate production and fatty acid profile of Neochloris oleoabundans HK-129 by a two-stage process," Bioresource Technology, vol. 155, pp. 204212, 2014.

[26] L.-D. Zhu and E. Hiltunen, "Methylation of DACT2 accelerates esophageal cancer development by activating Wnt signaling," Renewable and Sustainable Energy Reviews, vol. 54, pp. 12851290, 2016.

[27] G. Sibi, V. Shetty, and K. Mokashi, "Enhanced lipid productivity approaches in microalgae as an alternate for fossil fuels-a review," Journal of the Energy Institute, vol. 89, no. 3, pp. 330334, 2016.

[28] A. Converti, A. A. Casazza, E. Y. Ortiz, P. Perego, and M. Del Borghi, "Effect of temperature and nitrogen concentration on the growth and lipid content of Nannochloropsis oculata and 
Chlorella vulgaris for biodiesel production," Chemical Engineering and Processing: Process Intensification, vol. 48, no. 6, pp. 1146-1151, 2009.

[29] L. Xin, H. Hong-ying, and Z. Yu-ping, "Growth and lipid accumulation properties of a freshwater microalga Scenedesmus sp. under different cultivation temperature," Bioresource Technology, vol. 102, no. 3, pp. 3098-3102, 2011.

[30] J. Cao, H. Yuan, B. Li, and J. Yang, "Significance evaluation of the effects of environmental factors on the lipid accumulation of Chlorella minutissima UTEX 2341 under low-nutrition heterotrophic condition," Bioresource Technology, vol. 152, pp. 177184, 2014.

[31] L. Wei, X. Huang, and Z. Huang, "Temperature effects on lipid properties of microalgae Tetraselmis subcordiformis and Nannochloropsis oculata as biofuel resources," Chinese Journal of Oceanology and Limnology, vol. 33, no. 1, pp. 99-106, 2015.

[32] G. O. James, C. H. Hocart, W. Hillier, G. D. Price, and M. A. Djordjevic, "Temperature modulation of fatty acid profiles for biofuel production in nitrogen deprived Chlamydomonas reinhardtii," Bioresource Technology, vol. 127, pp. 441-447, 2013.

[33] X. Li, P. Přibyl, K. Bišová et al., "The microalga Parachlorella kessleri-a novel highly efficient lipid producer," Biotechnology and Bioengineering, vol. 110, no. 1, pp. 97-107, 2013.

[34] R. D. Gardner, E. Lohman, R. Gerlach, K. E. Cooksey, and B. M. Peyton, "Comparison of $\mathrm{CO}_{2}$ and bicarbonate as inorganic carbon sources for triacylglycerol and starch accumulation in Chlamydomonas reinhardtii," Biotechnology and Bioengineering, vol. 110, no. 1, pp. 87-96, 2013.

[35] E. Y. O. Montoya, A. A. Casazza, B. Aliakbarian, P. Perego, A. Converti, and J. C. M. De Carvalho, "Production of Chlorella vulgaris as a source of essential fatty acids in a tubular photobioreactor continuously fed with air enriched with $\mathrm{CO}_{2}$ at different concentrations," Biotechnology Progress, vol. 30, no. 4, pp. 916-922, 2014.

[36] A. Widjaja, C.-C. Chien, and Y.-H. Ju, "Study of increasing lipid production from fresh water microalgae Chlorella vulgaris," Journal of the Taiwan Institute of Chemical Engineers, vol. 40, no. 1, pp. 13-20, 2009.

[37] A. Nakanishi, S. Aikawa, S.-H. Ho et al., "Development of lipid productivities under different $\mathrm{CO}_{2}$ conditions of marine microalgae Chlamydomonas sp. JSC4," Bioresource Technology, vol. 152, pp. 247-252, 2014.

[38] M. Ota, Y. Kato, H. Watanabe et al., "Fatty acid production from a highly $\mathrm{CO}_{2}$ tolerant alga, Chlorocuccum littorale, in the presence of inorganic carbon and nitrate," Bioresource Technology, vol. 100, no. 21, pp. 5237-5242, 2009.

[39] S.-H. Ho, C.-Y. Chen, and J.-S. Chang, "Effect of light intensity and nitrogen starvation on $\mathrm{CO}_{2}$ fixation and lipid/carbohydrate production of an indigenous microalga Scenedesmus obliquus CNW-N," Bioresource Technology, vol. 113, pp. 244-252, 2012.

[40] G. Breuer, P. P. Lamers, D. E. Martens, R. B. Draaisma, and R. H. Wijffels, "Effect of light intensity, $\mathrm{pH}$, and temperature on triacylglycerol (TAG) accumulation induced by nitrogen starvation in Scenedesmus obliquus," Bioresource Technology, vol. 143, pp. 1-9, 2013.

[41] L. D. Zhu, J. Takala, E. Hiltunen, and Z. M. Wang, "Recycling harvest water to cultivate Chlorella zofingiensis under nutrient limitation for biodiesel production," Bioresource Technology, vol. 144, pp. 14-20, 2013.

[42] Y. Li, F. Han, H. Xu et al., "Potential lipid accumulation and growth characteristic of the green alga Chlorella with combination cultivation mode of nitrogen $(\mathrm{N})$ and phosphorus (P)," Bioresource Technology, vol. 174, pp. 24-32, 2014.

[43] I. Brányiková, B. Maršálková, J. Doucha et al., "Microalgaenovel highly efficient starch producers," Biotechnology and Bioengineering, vol. 108, no. 4, pp. 766-776, 2011.

[44] A. O. Alabi, M. Tampier, and E. Bibeau, "Microalgae technologies and processes for biofuels/bioenergy production in British Columbia," Current Technology, Suitability and Barriers to Implementation. Final Report, The British Columbia Innovation Council. Seed Science Press, 2009.

[45] T. Ito, M. Tanaka, H. Shinkawa et al., "Metabolic and morphological changes of an oil accumulating trebouxiophycean alga in nitrogen-deficient conditions," Metabolomics, vol. 9, no. 1, pp. 178-187, 2013.

[46] S. Mandal and N. Mallick, "Microalga Scenedesmus obliquus as a potential source for biodiesel production," Applied Microbiology and Biotechnology, vol. 84, no. 2, pp. 281-291, 2009.

[47] A. Sato, R. Matsumura, N. Hoshino, M. Tsuzuki, and N. Sato, "Responsibility of regulatory gene expression and repressed protein synthesis for triacylglycerol accumulation on sulfurstarvation in Chlamydomonas reinhardtii," Frontiers in Plant Science, vol. 5, article 444, 2014.

[48] B. Fernandes, J. Teixeira, G. Dragone et al., "Relationship between starch and lipid accumulation induced by nutrient depletion and replenishment in the microalga Parachlorella kessleri," Bioresource Technology, vol. 144, pp. 268-274, 2013.

[49] P. Přibyl, V. Cepák, and V. Zachleder, "Production of lipids in 10 strains of Chlorella and Parachlorella, and enhanced lipid productivity in Chlorella vulgaris," Applied Microbiology and Biotechnology, vol. 94, no. 2, pp. 549-561, 2012.

[50] A. Richmond, "Cell response to environmental factors," in CRC Handbook of Microalgal Mass Culture, A. Richmond, Ed., pp. 89-95, CRC Press, Florida, Fla, USA, 1986.

[51] F. Alkayal, R. L. Albion, R. L. Tillett, L. T. Hathwaik, M. S. Lemos, and J. C. Cushman, "Expressed sequence tag (EST) profiling in hyper saline shocked Dunaliella salina reveals high expression of protein synthetic apparatus components," Plant Science, vol. 179, no. 5, pp. 437-449, 2010.

[52] A. F. Talebi, M. Tabatabaei, S. K. Mohtashami, M. Tohidfar, and F. Moradi, "Comparative salt stress study on intracellular ion concentration in marine and salt-adapted freshwater strains of microalgae," Notulae Scientia Biologicae, vol. 5, no. 3, pp. 309315, 2013.

[53] H. Yang, Q. He, J. Rong, L. Xia, and C. Hu, "Rapid neutral lipid accumulation of the alkali-resistant oleaginous Monoraphidium dybowskii LB50 by NaCl induction," Bioresource Technology, vol. 172, pp. 131-137, 2014.

[54] A. Kirrolia, N. R. Bishnoia, and N. Singh, "Salinity as a factor affecting the physiological and biochemical traits of Scenedesmus quadricauda," Journal of Algal Biomass Utilization, vol. 2, pp. 28-34, 2011.

[55] M. Takagi, Karseno, and T. Yoshida, "Effect of salt concentration on intracellular accumulation of lipids and triacylglyceride in marine microalgae Dunaliella cells," Journal of Bioscience and Bioengineering, vol. 101, no. 3, pp. 223-226, 2006.

[56] X. Duan, G. Y. Ren, L. L. Liu, and W. X. Zhu, "Salt-induced osmotic stress for lipid overproduction in batch culture of Chlorella vulgaris," African Journal Biotechnology, vol. 11, no. 27, pp. 7072-7078, 2012.

[57] H.-Y. Ren, B.-F. Liu, F. Kong, L. Zhao, G.-J. Xie, and N.-Q. Ren, "Enhanced lipid accumulation of green microalga Scenedesmus 
sp. by metal ions and EDTA addition," Bioresource Technology, vol. 169, pp. 763-767, 2014.

[58] J. Yang, J. Cao, G. Xing, and H. Yuan, "Lipid production combined with biosorption and bioaccumulation of cadmium, copper, manganese and zinc by oleaginous microalgae Chlorella minutissima UTEX2341," Bioresource Technology, vol. 175, pp. 537-544, 2015.

[59] Z.-Y. Liu, G.-C. Wang, and B.-C. Zhou, "Effect of iron on growth and lipid accumulation in Chlorella vulgaris," Bioresource Technology, vol. 99, no. 11, pp. 4717-4722, 2008.

[60] Y. Li, J. Mu, D. Chen et al., "Production of biomass and lipid by the microalgae Chlorella protothecoides with heterotrophic$\mathrm{Cu}$ (II) stressed (HCuS) coupling cultivation," Bioresource Technology, vol. 148, pp. 283-292, 2013.

[61] G. Mujtaba, W. Choi, C.-G. Lee, and K. Lee, "Lipid production by Chlorella vulgaris after a shift from nutrient-rich to nitrogen starvation conditions," Bioresource Technology, vol.123, pp. 279283, 2012.

[62] C. Adams, V. Godfrey, B. Wahlen, L. Seefeldt, and B. Bugbee, "Understanding precision nitrogen stress to optimize the growth and lipid content tradeoff in oleaginous green microalgae," Bioresource Technology, vol. 131, pp. 188-194, 2013.

[63] Y. Zhao, D. Li, K. Ding et al., "Production of biomass and lipids by the oleaginous microalgae Monoraphidium sp. QLY-1 through heterotrophic cultivation and photo-chemical modulator induction," Bioresource Technology, vol. 211, pp. 669-676, 2016.

[64] P. Feng, Z. Deng, L. Fan, and Z. Hu, "Lipid accumulation and growth characteristics of Chlorella zofingiensis under different nitrate and phosphate concentrations," Journal of Bioscience and Bioengineering, vol. 114, no. 4, pp. 405-410, 2012.

[65] L. Xin, H. Hong-ying, and Y. Jia, "Lipid accumulation and nutrient removal properties of a newly isolated freshwater microalga, Scenedesmus sp. LX1, growing in secondary effluent," New Biotechnology, vol. 27, no. 1, pp. 59-63, 2010.

[66] P. D. Álvarez-Díaz, J. Ruiz, Z. Arbib, J. Barragán, C. GarridoPérez, and J. A. Perales, "Lipid production of microalga Ankistrodesmus falcatus increased by nutrient and light starvation in a two-stage cultivation process," Applied Biochemistry and Biotechnology, vol. 174, no. 4, pp. 1471-1483, 2014.

[67] S. Ota, K. Oshima, T. Yamazaki et al., "Highly efficient lipid production in the green alga Parachlorella kessleri: draft genome and transcriptome endorsed by whole-cell 3D ultrastructure," Biotechnology for Biofuels, vol. 9, article 13, 2016.

[68] Y. Mizuno, A. Sato, K. Watanabe et al., "Sequential accumulation of starch and lipid induced by sulfur deficiency in Chlorella and Parachlorella species," Bioresource Technology, vol. 129, pp. 150-155, 2013. 

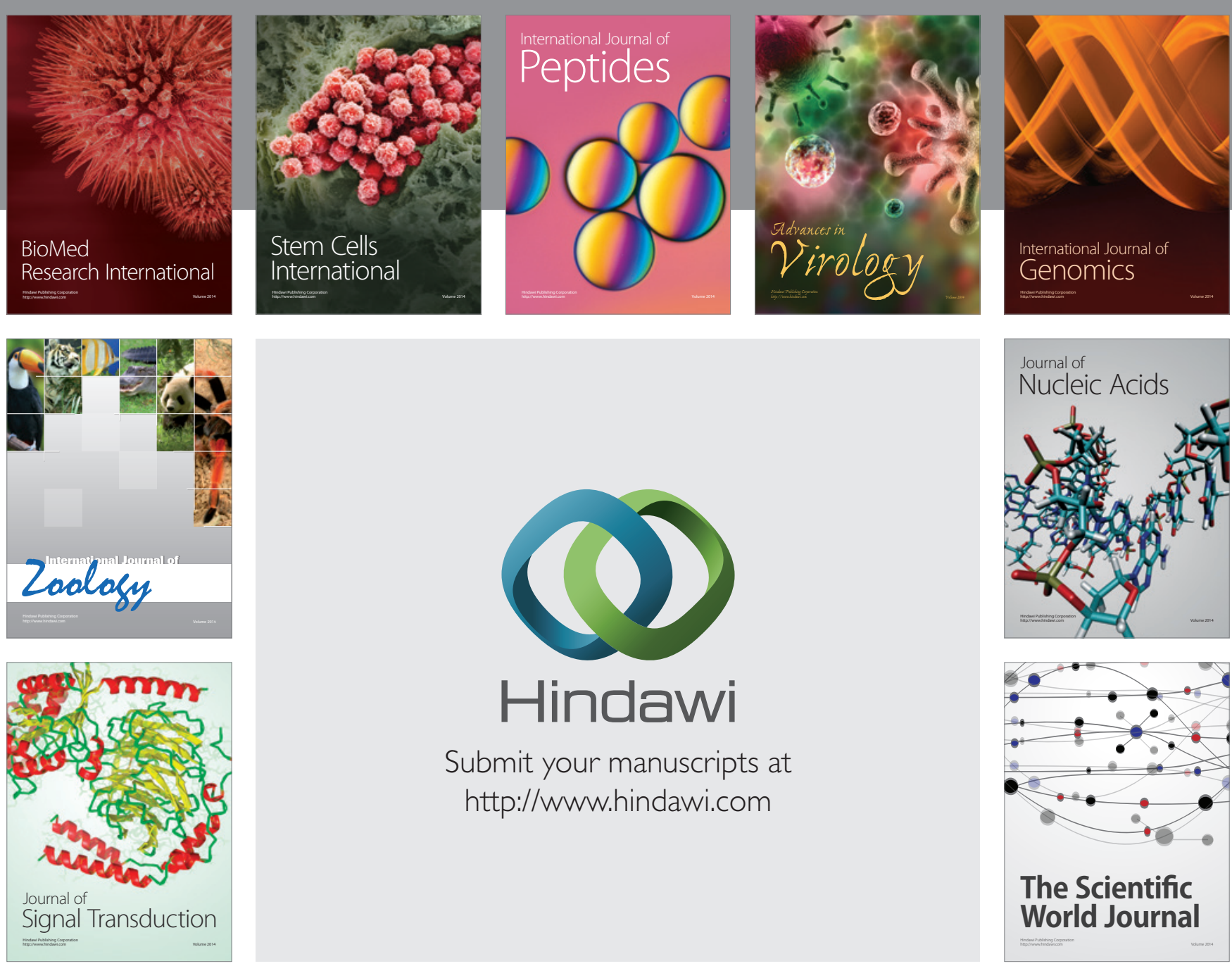

Submit your manuscripts at

http://www.hindawi.com
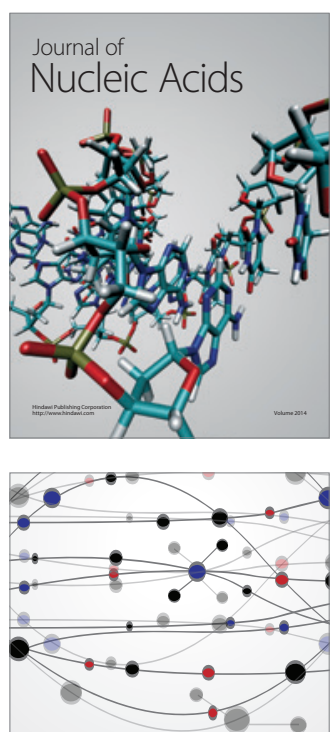

The Scientific World Journal
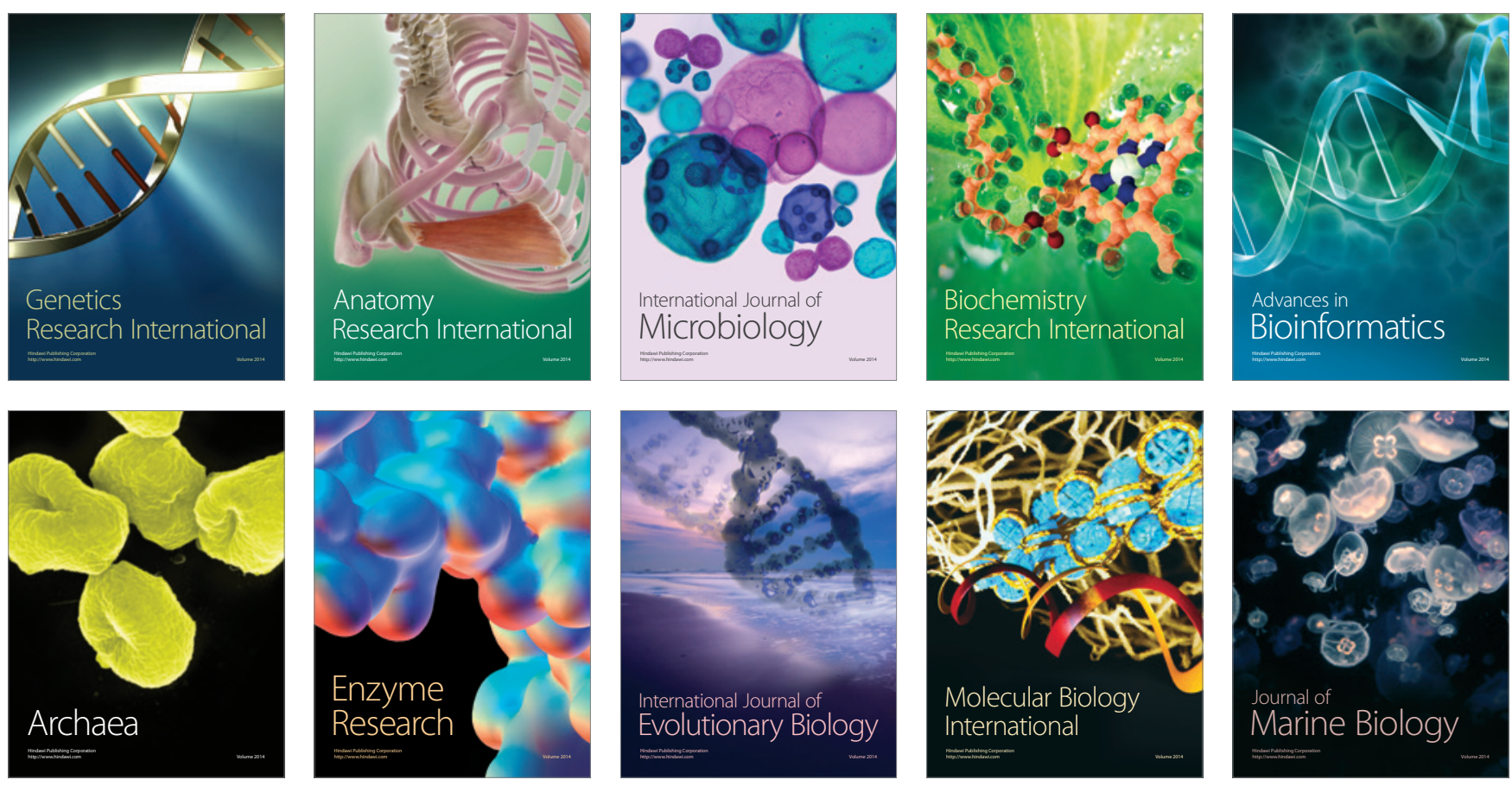